\title{
Profitability, Productivity and Price Recovery Patterns in the U.S. Telecommunications Industry
}

\author{
R. D. BANKER ${ }^{1}$, H.-H. CHANG ${ }^{2}$ and S. K. MAJUMDAR ${ }^{3}$ \\ ${ }^{1}$ Carlson School of Management, University of Minnesota, Minneapolis MN, U.S.A., ${ }^{2}$ Hsi-hui \\ Chang, College of Commerce, National Chengchi University, Taipei, Taiwan; ${ }^{3}$ School of Business \\ Administration, The University of Michigan, Ann Arbor, MI, U.S.A.
}

\begin{abstract}
We undertake a study where we examine changes in the profitability, productivity and price recovery of firms in the U.S. telecommunications industry over a sixteen-year period. We assess the performance of thirty-three major companies in the local-exchange sector over six time periods $1975,1978,1981,1984,1987$ and 1990, using a performance analysis model which disaggregates the profitability measure into two components: productivity and price recovery. We demonstrate the computation of performance using this technique. Our study indicates that the opening up of markets has had a significant impact on different dimensions of performance in the telecommunications industry, also validating a number of theoretical assumptions about the impact that industry changes are expected to have on firms.
\end{abstract}

Key words: Productivity, performance analysis, telecommunications.

JEL Classification: L96 (Telecommunications), M40 (Accounting: General)

\section{Introduction}

The liberalization of markets, leading to changes in the performance of participant firms, is a major item on the institutional agenda of nations, with lessons to be gleaned from the U.S. telecommunications industry, where the world's biggest regulated industry has gradually opened to competition. In this empirical note we evaluate if different performance parameters of firms providing telecommunications services in the U.S. have changed significantly as a result of the institutional changes that have taken place. In carrying out the empirical component of the study we use a model of disaggregated performance measurement which allows for the decomposition of firms' profitability into their productivity and price recovery components. A variant of the technique has been used to assess the performance of individual firms (Banker, Chang and Majumdar, 1993, 1995). However, its use in evaluating assumptions from economic theory, which may help explain firm-level responses to changes in market conditions, has been limited and the present paper is an extension of the earlier work. The paper is structured as follows. In Section II we describe the telecommunications industry, and the events that have taken place. 
In Section III we have a discussion of the general implications of market liberalization on firm-level behavior. In Section IV we describe the research method used. Results and discussion follow in Section V, and Section VI sums up the paper.

\section{The Context}

The U.S. telecommunications services industry has historically been comprised of two major segments, the local exchange sector and the long-distance sector. Local exchange companies account for the bulk of the telephone revenues in the country, and comprise the sector we study. They control the "last mile" of the network, which has given them their local monopoly status, and are responsible for services to both business and residential customers. They have also been responsible for providing in-state long-distance services. Long-distance companies, the primary company being AT\&T Long Lines (now AT\&T Communications), have been historically responsible for inter-state (and since 1984 inter-LATA) long-distance services. There are over fourteen hundred local-exchange companies; however, of these about fifty account for about ninety-five percent of local company revenues and have included Fortune 100 giants such as Pacific Bell, Southern Bell and Southwestern Bell Telephone, each with billions of dollars of annual revenues and many thousands of employees. The local companies have historically used their business and long-distance subscribers to cross-subsidize local residential customers. The bulk of the costs of telephone operations, on the other hand, are spent on non-traffic sensitive plant to interconnect local households; however, the primary sources of revenues have been the business and long-distance customers (Vietor, 1989), and in the decade of the eighties this sector has become prospectively competitive (Wenders, 1989).

The principal liberalization event in the U.S. telecommunications industry took place in 1984, with the divestiture by AT\&T of its local operating companies. However, since 1956 a series of events has gradually changed the competitive fabric of the industry. These events attempted to convert monopoly markets into arenas where monopolistic competition could be sustainable in different segments. The primary motive was to challenge the AT\&T dominance of the industry, on the grounds that the industry was lagging behind in efficiency and innovation as a result. The key events, all of which affected the local operating companies as well as the long-distance carriers, have been as follows, and their implications for making the market structure in the industry more competitive is also discussed. In 1959 the "Above 890 " decision opened the way for private networks to bypass the switched networks. Thus, key business customers, if they were able to afford it, could construct their own private telephone facilities, either locally or over longdistance. In 1968 the "Carterfone" decision allowed customers to connect their own equipment to the network. Thus, the network's monopoly over equipment rental was ended. If necessary, customers could replicate their entire internal phone systems with their own equipment. The 1969 "MCl" decision allowed new networks to be 
built for the first time to be competitive with the existing networks, though initially the competitive impact was felt in the long-distance services area, both intra-state and inter-state.

The above measures made the industry structure more competitive, akin to monopolistic competition, by allowing alternative suppliers entry into certain key segments. These segments were the highly profitable business sector which had cross-subsidized local residential services. The market liberalization process allowed facilities-based entry. Prices were still subject to local regulatory oversight, and pricing flexibility or price-based competition did not occur till the 1977 "Execunet" decision, which allowed price competition in the long-distance sector. The impact of these decisions has been to make certain key, high cash-flow yielding markets open to competition, in many cases challenging the monopoly positions of either AT\&T owned (now Regional Holding Company [RHC]) operating companies, other companies or the long-distance carriers. In 1984, the divestiture decree, implemented as a result of the implementation of the 1983 Modified Final Judgment given with respect to the revived 1981 anti-trust suit against AT\&T, had the impact of breaking up the AT\&T monopoly and distributing the assets among several players. It also made the long-distance sector fully open to competition, and made the local operating companies not only responsible for the local monopoly business, but also for a host of other businesses where competitive entry, based on facilities and price competition, was feasible (Bolter, McConnaughey and Kelsey, 1990).

\section{Theory}

Because liberalization makes market entry easier, at a macro level of analysis the key effect is to increase the number of suppliers, with no change, however, in the number of buyers. This causes a drop in the overall price-cost margins, since entrants come in with a lower price to capture market share, forcing existing firms to drop their prices (Spence, 1977). Since high price-cost (profitability) margins are correlated with monopoly power (Cowling and Waterson, 1976; Shepherd, 1990), when monopoly power is reduced the primary impact is on firms' profitability margins. Existing firms may then try to compensate for falling prices by being more efficient, exploiting initial opportunities before other entrants come in, and earning the same or higher margins in the short run; however, long run margins are likely to stabilize at some prior level because of the reduction of incentives for efforts to attaining efficiency.

Spence (1986, p. 477) makes the following comment in the context of a market becoming competitive and where firms undertake measures to improve their efficiency: "Competition has two conflicting effects on process $R \& D$ and technical efficiency. It creates downward price pressures for individual firms: that has the effect of increasing incentives to carry out $R \& D$ and hence of improving technical efficiency. But as the number of firms increases market shares fall. Reduced sales 
dilute the incentives to reduce costs because the cost-reduction expenditures are fixed given the rate of cost decline, while the benefits decline as market shares fall."

The impact of increasing competition then can be ambiguous. In some cases dynamic profitability can rise as existing firms take advantage of the liberalized environment to make higher sales through new product introductions, and as concentration declines are also spurred towards better internal performance. However, with increasing entry margins are likely to fall as market shares decline, and this will be regardless of the ability of firms to maximize revenues or minimize costs. Hence, margins will fall because benefits from costs savings are eventually going to be less than the revenue losses from the decline in prices. Nevertheless, there may be an early period following deregulation in which margins do rise because newer entrants have not yet made their mark in the market.

For the local operating companies, bypass, which means the use of facilities other than that of the local operating companies, has been prevalent since the "Above 890 " decision of 1959 , but has exacerbated since the 1970 s. This has been driven by developments in alternative technologies such as radio-based, cable-based, and switching-based communication systems (Gill, McFarlan and O'Neill, 1989). Larger business customers, thus, have had the ability to not use local operating companies' facilities except for very marginal needs. The situation has substantially altered in the 1980s with the introduction of the cellular phone, which serves to take away from the local operating companies a major chunk of their higher revenue generating customers. Though customers who use bypass services may have to pay access charges to the local companies, such charges do not nearly match the revenue losses suffered by these companies, particularly in high-density metropolitan areas which contain the most profitable customers (Meyer, Wilson, Baughcum, Burton and Caouette, 1980; Mitchell and Vogelsang, 1991).

A second type of competitive pressure on local operating companies is intraLATA competition. Long-distance carriers have exclusive privileges for inter-state, or since 1984 inter-LATA long-distance services provision. In many states the local operating companies have had monopoly rights over long-distance service provisions within LATA's falling in their jurisdiction. However, many states, particularly populous ones such as Illinois, Massachusetts, Michigan, Ohio and Pennsylvania, allow intra-LATA long-distance competition (Bolter, McConnaughey and Kelsey, 1990; Huber, 1987). Local operating companies have to provide these competitors equal access to their networks for call delivery, though the access revenues earned are often less than the long-distance revenues lost. Also, if some local operating companies do not provide cqual access to their intra-LATA competitors, the installed base of long-distance lines maintained by other long-distance companies are available to these intra-LATA service providers for a fee. For example, many long-distance companies lease lines in wholesale from AT\&T, MCI and Sprint and are able to offer services at lower prices than those charged by the local operating companies or the main long-distance companies. Notwithstanding pressures on 
revenues, the local network and plant owned by the operating companies have to be kept in place as they are. They account for most of the costs of a local operating company, cannot be dismantled, and have to stay in place for access to be available for all. Even if efficiencies in operations are attained, there are finite limits to these, and the steady erosion of revenues means declining profitability over time as competitive forces exacerbate.

Next, a more competitive environment becomes the biggest spur to attain efficiency in operations analysis, since costs cannot be passed on to consumers any longer. Wastages, slack in input utilization, and inflated wage costs are no longer tolerated (Kahn, 1988). Without increasing productivity, in increasingly competitive environments the long-run survival of the firm can be in doubt (Crew, JonesLee and Rowley, 1971), and liberalization induces pressures on firms to increase productivity (Leibenstein, 1976; Selten, 1986). In this aspect, several studies of the telecommunications industry (Bailey, 1986; Crandall, 1991; Majumdar, 1995) show rising productivity following liberalization, thus empirically supporting conjectures positing significant scope for productivity improvements among local operating companies. Within the context of the U.S. telecommunications industry the issue of whether the productivity of firms is likely to arise from technological reasons or better utilization of human resources is relevant, given the changes in technological regimes. However, unlike the trucking industry where deregulation has led to the decline of rents of labor (Rose, 1987), Crandall (1991) notes that in the telecommunications industry relative wage rates have not fallen; instead, his empirical tests find better usage of human capital, in combination with faster adoption of digital switching, leading to substantial improvements in technical efficiency.

Finally, in monopolistic or oligopolistic markets, demand for a firm's products may be inelastic and the producer can equate marginal revenue with marginal costs to maximize profits. Also, in a relatively non-monopolistic market, where search is costly for new firms and the possibility of entry is non-instantaneous, a dominant firm can collude to not allow new entrants entry, and enjoy prices near the monopoly level (Gaskins, 1971; Kamien and Schwartz, 1971). However, changing technology in telecommunications has permitted the minimum efficient scale size to become small enough to permit several viable competitors to enter, and enable new product offerings to take place and alternate sources of supply to be made available in many once-lucrative market segments (Shepherd, 1983). Coupled with the progressive introduction of competition, in such scenarios the demand curve faced by an erstwhile monopoly supplier becomes flatter and more elastic, and new competitors can charge lower prices to attract customers. Institutional changes imply that customers who have not had choices of changing their suppliers earlier now do have such choices. This means that existing suppliers have to drop their prices towards the marginal costs of supply, and such measures lead to drops in the price-recovery ability of firms. 
For example, Bailey (1986) finds lowered prices as a result of market liberalization in the airlines, telecommunications, financial services and trucking industries; this trend is also borne out by Perl (1988) in a study of prices in the post-divestiture telecommunications industry. Similarly, Crandall (1991) has noted that over the period 1977 to 1983 real telephone services prices dropped 3.7\%, and the biggest drops were in interstate and intrastate toll services of 5\% and 5.6\% respectively though local prices also dropped 2.5\%. In the period 1983 to 1988 services prices decreased $.3 \%$ but there was an increase of $3.9 \%$ in local prices while interstate and intrastate toll prices dropped $10.2 \%$ and $3.2 \%$ respectively. Given that toll prices on a per-minute basis are the profit sanctuaries of telephone firms, such overall price declines prognosticate an overall trend of firms in the industry to not recover premium prices.

The above consequences of competition can be illustrated analytically. On the supply side, the production function is typically given by $y=y(K, L)$, where $y$ is the physical quantity of output, $K$ the quantity of capital employed, and $L$ the quantity of labor input. We may include the effect of competition by specifying a parameter $\theta$ to capture (exogenously) the degree of competition in the market (e.g., the number of firms in the market), and restate the production function as

$$
y=y(K, L, \theta), \partial y / \partial \theta>0,
$$

since competition is likely to have the effect of reducing organizational slack. In consequence, the marginal cost curve shifts downwards as $\theta$ increases (see Figure 1). If there were no demand-side effects (i.e., the average revenue and marginal revenue curves were not affected by the degree of competition), the effect of greater competition would be to lower output prices and increase the output quantity.

There will, of course, be a demand-side effect of competition. In particular, we should expect the firm-level (selective) demand to exhibit the following characteristics relative to monopolistic demand:

(a) At any given price, the firm-level demand in a competitive (multifirm) market will be lower than the corresponding monopolistic demand; and

(b) At any given price, the price elasticity of the firm-level (selective) demand will be greater than that of monopolistic demand.

The demand function at the firm level may be stated as

$$
y=y(p, \theta), \partial y / \partial \theta<0, \text { and } \partial \eta / \partial \theta>0,
$$

where $p$ is the price level and $\eta$ is the absolute value of the price elasticity of demand, $\eta=-\frac{\partial y}{\partial p} \cdot \frac{p}{y}$. Under these conditions, the demand-side effect of competition is to decrease the profit-maximizing output price and also to decrease the output quantity. With both supply and demand side effects operating simultaneously, increased competition has an unambiguous downward impact on price. For example, compare $p^{*}\left(\theta_{1}\right)$ with $p^{*}\left(\theta_{0}\right)$ in Figure 1. The impact on quantity is ambiguous, in that it is conceivable that the firm-level output could actually increase with greater competition. This is unlikcly, for cxample, with the shift in 


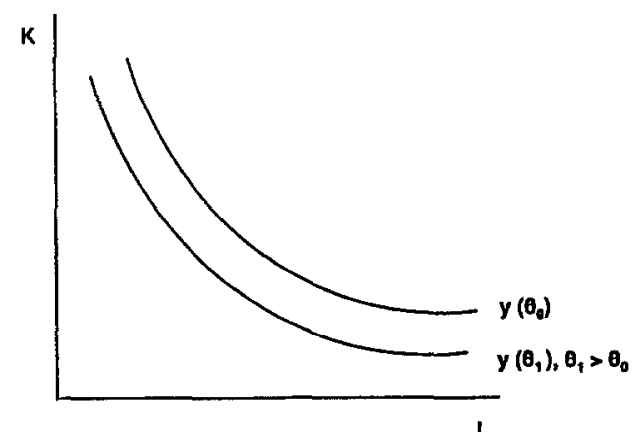

(a) Production Function

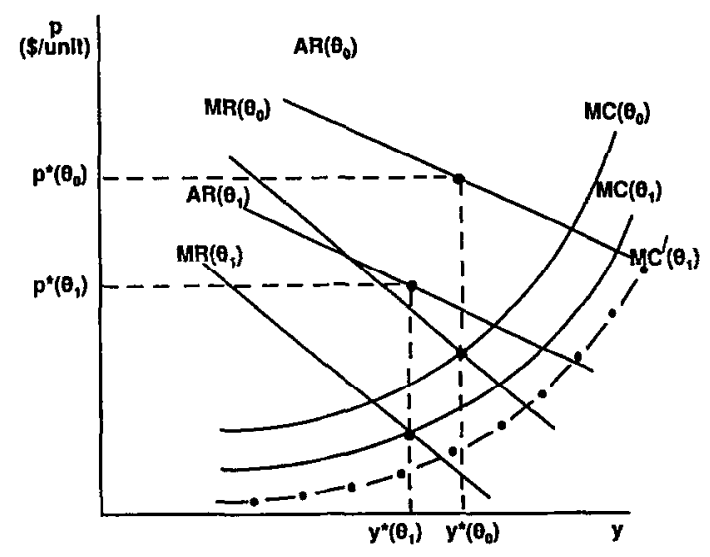

(b) Profit Maximizing Price and Output Lovels

Fig. 1. Supply-and demand-side effects of competition.

the MC curve as shown in Figure $1, y^{*}\left(\theta_{1}\right)$ is less than $y^{*}\left(\theta_{0}\right)$, but possible in a situation where the increase in efficiency on account of competition leads to a dramatic shift downward in the marginal cost curve (the curve $M C^{\prime}\left(\theta_{1}\right)$ instead of $M C\left(\theta_{1}\right)$ in Figure 1).

Thus, the effect of competition is expected to exert a downward pressure on output prices. The demand-side effect alone on profits is clearly negative (since both prices and quantity are adversely affected), although this adverse impact is at least partially mitigated by the supply side effect of greater operating efficiency. To the extent that firms become more efficient in anticipation of competition, the supply-side benefits may be felt first, resulting in higher productivity and profitability for some period of time, until competitors actually establish themselves and profitability declines probably to below monopoly levels. 


\section{Research Setting and Method}

\section{A. ChOice of Sector for Study and How Performance is COMPARED}

We have already described that though local operating companies are still subject to major regulation, in their key profit sanctuaries the winds of competition have blown since the late 1960s and early 1970s. We test our expectations from theory and evaluate the performance of these companies for 1975, 1978, 1981, 1984, 1987 and 1990.1975 is an ideal period to initially anchor the study since prior to that year not many measures to liberalize the industry had taken place. By 1978 some market-opening measures were being implemented and price-competition was first allowed into the industry. In 1981 political moves to liberalize began after the Reagan administration took office, culminating in the 1984 divestiture. Thus, we have an overall span of sixteen years, critical in the history of the industry, wherein we can evaluate the impact of market liberalization of firms. The three-year gap between each time period also enables dynamic lags to be factored through. Since there was a recessionary period from 1979 to 1982, data points before and after this period also enable us to judge the effects of liberalization.

\section{B. Performance Ratios Used to Analyze Performance}

We use input, output and price data for each firm for each of $t(t=1, \ldots T)$ time-periods (where $t=1 \ldots 6$ ). In period $t$, the firm utilizes $x_{n}^{t}$ units of each $n=1, \ldots N$ inputs to produce $y_{m}^{t}$ units of cach $m=1, \ldots M$ outputs. The price of input $n$ in period $t$ is $w_{n}^{t}$, and the price of output $m$ is $p_{m}^{t}$. Thus, total revenues add up to $\sum_{m=1}^{M} p_{m}^{t} y_{m}^{t}>0$, and the total costs amount to $\sum_{n=1}^{N} w_{n}^{t} x_{n}^{t}>0$, yielding a profit of $\sum_{m=1}^{M} p_{m}^{t} y_{m}^{t}-\sum_{n=1}^{N} w_{n}^{t} x_{n}^{t}$. The profitability ratio for period $t$ is $\pi^{t}=$ $\sum_{m=1}^{M} p_{m}^{t} y_{m}^{t} / \sum_{n=1}^{N} w_{n}^{t} x_{n}^{t}$ and the profitability change ratio $P F T B L T=\pi^{t} / \pi^{0}$. Thus,

$$
\operatorname{PFTBLT}=\frac{\sum_{m=1}^{M} p_{m}^{t} y_{m}^{t}}{\sum_{n=1}^{N} w_{n}^{t} x_{n}^{t}} / \frac{\sum_{m=1}^{M} p_{m}^{o} y_{m}^{o}}{\sum_{n=1}^{N} p_{n}^{o} y_{n}^{o}} .
$$

Depending on the purpose of the analysis, the base level 0 can be defined as a firm's own performance during some period in the past, as some technically determined standard, as another firm's performance, or as the performance of the industry as a whole. In this study our interest is in comparing the performance of the firms that make up the local operating sector; thus, we use average prices and quantities for the sector as a whole, pooled for the six periods, to compute the base level ratio.

The production technology relating the inputs and outputs is assumed to be a generalized fixed-proportions technology. That is, the standard input requirement $\left(Z_{n}\right)$ 
for an input $n$, corresponding to the production of outputs $y=\left(y_{1}, K y_{m}, K y_{M}\right)$ is given by

$$
Z_{n}=g_{n}(y) \text { for } n=1 \ldots N
$$

with $z_{n}>0$ for $y>0$. In addition, the focus of this paper is long-term inter-period analysis, and we assume that costs are linear and variable in the long run. That is

$$
Z_{n}=\sum_{m=1}^{M} \psi_{m n} y_{m}
$$

where $\psi_{m n}>0$ is the standard input requirement for a unit of output $(m)$. We refer to this as the standard production technology assumption.

For further analysis, an approach suggested by the American Productivity Center (APC) can be used to decompose the profitability change ratio in (3) into its productivity and price recovery parts. The productivity change ratio is defined as the ratio of the value of current level output to base level output, divided by the ratio of the value of current-period inputs to base level inputs. The productivity change ratio measures the technical efficiency of firms. The price recovery ratio is defined as the ratio of the value of outputs at current period prices to the value at base level prices, divided by the value of inputs at current period prices to the value at base level prices. The price recovery ratio helps measure the abilities of firms to be price or allocatively efficient.

The APC method has only been described briefly before via numerical examples (Banker, Datar and Kaplan, 1989; Kendrick, 1986), and its use is particularly apposite when a composite measure of performance such as profitability requires decomposition, so as to capture different elements, such as the impact of efficient resource utilization or allocative efficiency, that are subsumed within it (Shepherd, 1986). It is a particularly useful technique to test the assumptions underlying the theory of industrial organization. We outline the APC method, representing it algebraically, via seven steps. STEP 1: Compute an output value change ratio

$$
O V C=\sum_{m=1}^{M} p_{m}^{t} y_{m}^{t} / \sum_{m=1}^{M} p_{m}^{o} y_{m}^{o}
$$

STEP 2: Compute a weighted average of the output quantity changes

$$
\begin{aligned}
O Q C & =\sum_{m=1}^{M}\left[p_{m}^{o} y_{m}^{o}\left(y_{m}^{t} \mid y_{m}^{o}\right) / \sum_{j=1}^{M} p_{j}^{o} y_{j}^{o}\right] \\
& =\sum_{m=1}^{M} p_{m}^{o} y_{m}^{t} / \sum_{m=1}^{M} p_{m}^{o} y_{m}^{o}
\end{aligned}
$$


where the weights are the revenue shares, $j$, of the different outputs in period 0 . STEP 3: Compute an output price change index

$$
O P C=O V C / O Q C=\sum_{m=1}^{M} p_{m}^{t} y_{m}^{t} / \sum_{m=1}^{M} p_{m}^{o} y_{m}^{t} .
$$

STEP 4: Compute a partial input productivity change measure

$$
I P C_{n}=O Q C /\left(x_{n}^{t} \mid x_{n}^{o}\right), n \ldots N
$$

as the ratio of the output quantity change index to the quantity change for each input.

STEP 5: Compute the aggregate productivity change ratio, APRDT, as the weighted average of the partial input productivity scores,

$$
\begin{aligned}
A P R D T & =\sum_{n=1}^{N} w_{n}^{t} x_{n}^{t}\left(I P C_{n}\right) / \sum_{k=1}^{N} w_{k}^{t} x_{k}^{t} \\
& =\left[\sum_{m=1}^{M} p_{m}^{o} y_{m}^{t} / \sum_{m=1}^{M} p_{m}^{o} y_{m}^{o}\right] \mid\left[\sum_{n=1}^{N} w_{n}^{t} x_{n}^{t} / \sum_{n=1}^{N} w_{n}^{t} x_{n}^{o}\right]
\end{aligned}
$$

where the weights are the cost shares, $k$, of the inputs $\left(=w_{n}^{t} x_{n}^{t} / \sum_{n=1}^{N} w_{n}^{t} x_{n}^{o}\right)$ in
period $t$. STEP 6: Compute the profitability change ratio as in (1) and express it as the weighted sum of partial profitability change measures

$$
P R F_{n}=O V C \mid\left(w_{n}^{t} x_{n}^{t} / w_{n}^{o} x_{n}^{o}\right)
$$

The weights are again the input cost shares, so that

$$
\begin{aligned}
P F T B L T & =\sum_{n=1}^{N} w_{n}^{t} x_{n}^{t}\left(P R F_{n}\right) \mid \sum_{k=1}^{N} w_{k}^{t} x_{k}^{t} \\
& =\left[\sum_{m=1}^{M} p_{m}^{t} y_{m}^{t} \mid \sum_{m=1}^{M} p_{m}^{o} y_{m}^{o}\right] \mid\left[\sum_{n=1}^{N} w_{n}^{t} x_{n}^{t} \mid \sum_{n=1}^{N} w_{n}^{o} x_{n}^{o}\right] .
\end{aligned}
$$

STEP 7: Compute the price recovery change ratio $A P R C R=P F T B L T /$ $A P R D T$

$$
=\left[\sum_{m=1}^{M} p_{m}^{t} y_{m}^{t} / \sum_{m=1}^{M} p_{m}^{o} y_{m}^{t}\right] \mid\left[\sum_{n=1}^{N} w_{n}^{t} y_{n}^{o} / \sum_{n=1}^{N} w_{n}^{o} x_{n}^{o}\right] .
$$




\section{Data Sources Used to Calculate the Ratios}

There are about fifty major local telephonc opcrating companies in the U.S., with annual revenues of $\$ 100$ million or more. They include all erstwhile Bell operating companies, independent companies such as Rochester Telephone, and companies belonging to GTE, United Telecommunications, Central and the Continental groups. We calculate performance measures for thirty-three of these for six time pcriods: $1975,1978,1981,1984,1987$ and 1990. The other companies are not used because of missing data problems.

For the thirty-three companies whose performance we analyze, data is obtained from the annual Federal Communications Commission publication titled "Statistics of Communications Common Carriers". All telephone companies subject to reporting requirements, and even those not so subject, file financial and operating data with the Federal Communications Commission. These include detailed breakdown of revenues, costs, assets, physical outputs and physical assets.

To calculate the performance ratios certain basic data about a firm's operation are required. These include details of its outputs, the composition of its revenue streams, how the total operating expenses are composed, and details about the physical assets or resources that enable it to provide the products or services that it does. The following measures are used to compute the performance ratios.

\section{MEASURES OF OUTPUTS AND INPUTS}

We choose two physical output measures. These are the annual total number of local and toll calls respectively. Financial output measures are local and toll call revenues. Toll revenues also include access revenues earned by the companies because they permit their networks to be used by other long-distance companies, and miscellaneous revenues are split between local and toll revenues in the proportion that each bears to total operating revenues. Allied to the measures of output are inputs which are the operating costs incurred, which are maintenance and depreciation costs, while traffic, commercial, general office and other expenses are variable costs, which vary with the volume of activity.

\section{Analysis and Discussion of Results}

\section{A. GENERAL ANALYSIS}

Table I gives the descriptive statistics which show how the average performance ratios for all the firms in the industry have behaved from 1975 to 1990.

We find that profitability falls from 1975 to 1978 and from 1978 to 1981 . This is consistent with expectations. However, it rises in 1984 relative to 1981 following divestiture and the accompanying strategic changes, but then falls in 1987 relative to 1984 and in 1990 relative to 1987 . It is, of course, feasible that the recovery in 1984 may be a reaction of firms to improved opportunities following the recession 
TABLE I. Descriptive statistics

\begin{tabular}{|c|c|c|c|c|c|c|}
\hline \multicolumn{7}{|c|}{ Panel (a): Profitability change ratio } \\
\hline & 1975 & 1978 & 1981 & 1984 & 1987 & 1990 \\
\hline Mean & 1.091 & 1.083 & 1.031 & 1.044 & 1.013 & 0.929 \\
\hline Standard & 0.088 & 0.070 & 0.057 & 0.044 & 0.038 & 0.035 \\
\hline \multicolumn{7}{|l|}{ Deviation } \\
\hline Minimum & 0.950 & 0.959 & 0.916 & 0.961 & 0.928 & 0.865 \\
\hline Maximum & 1.289 & 1.227 & 1.151 & 1.125 & 1.113 & 1.009 \\
\hline \multicolumn{7}{|c|}{ Panel (b): Productivity change ratio } \\
\hline Mean & 0.642 & 0.726 & 0.790 & 1.096 & 1.273 & 1.523 \\
\hline Standard & 0.171 & 0.186 & 0.209 & 0.313 & 0.332 & 0.466 \\
\hline \multicolumn{7}{|l|}{ Deviation } \\
\hline Minimum & 0.302 & 0.399 & 0.421 & 0.656 & 0.742 & 0.794 \\
\hline Maximum & 1.345 & 1.497 & 1.696 & 2.376 & 2.396 & 2.344 \\
\hline \multicolumn{7}{|c|}{ Panel (c): Price recovery change ratio } \\
\hline Mean & 1.800 & 1.576 & 1.379 & 1.014 & 0.841 & 0.673 \\
\hline Standard & 0.451 & 0.376 & 0.327 & 0.256 & 0.194 & 0.225 \\
\hline \multicolumn{7}{|l|}{ Deviation } \\
\hline Minimum & 0.804 & 0.720 & 0.603 & 0.441 & 0.425 & 0.398 \\
\hline Maximum & 3.186 & 2.478 & 2.257 & 1.663 & 1.364 & 1.147 \\
\hline
\end{tabular}

of the early 1980s. The productivity change ratio rises monotonically from 1975 to 1990 , and the price recovery change ratio falls consistently, from 1975 to 1990 . From Table I it seems that the fall in profitability that takes place between 1975 and 1990 has been counter-balanced mainly by increasing productivity. While the price recovery ratio has dropped dramatically, the negative impact of such a drop has been somewhat mitigated by the concerted positive impact of the rise in productivity. Detailed results of the statistical tests carried out on the ratios are given in Table II. We evaluate if each ratio for a following is greater than that of the previous year. In Table II, the test carried out is to evaluate if the ratio for the row year is less than that of the column year. We use the Wilcoxon (1945) procedure and the cell numbers are the $z$-score, followed in parentheses by the probability value that the score is significantly different from zero.

\section{B. THE IMPACT ON PROFITABILITY}

Initially we posit that as markets became more competitive due to deregulation profitability over the long-run will decrease, but may rise in the immediate short run because of greater opportunities for incumbents to maximize revenues, while incentives to reduce costs will also increase. However, relative to such increases in 
TABLE II. Statistical test results

\begin{tabular}{|c|c|c|c|c|c|}
\hline \multicolumn{6}{|c|}{ Panel (a): Profitability } \\
\hline & 1978 & 1981 & 1984 & 1987 & 1990 \\
\hline \multirow[t]{2}{*}{1975} & -0.116 & -4.297 & -3.064 & -4.154 & -4.994 \\
\hline & $(0.91)$ & $(0.00)$ & $(0.00)$ & $(0.00)$ & $(0.00)$ \\
\hline \multirow[t]{2}{*}{1978} & & -4.85 & -3.814 & -4.583 & -5.011 \\
\hline & & $(0.00)$ & $(0.00)$ & $(0.00)$ & $(0.00)$ \\
\hline \multirow[t]{2}{*}{1981} & & & 2.028 & -1.885 & -4.923 \\
\hline & & & $(0.04)$ & $(0.06)$ & $(0.00)$ \\
\hline \multirow[t]{2}{*}{1984} & & & & -3.583 & -4.958 \\
\hline & & & & $(0.00)$ & $(0.00)$ \\
\hline \multirow[t]{2}{*}{1987} & & & & & -4.958 \\
\hline & & & & & $(0.00)$ \\
\hline \multicolumn{6}{|c|}{ Panel (b): Productivity } \\
\hline \multirow[t]{2}{*}{1975} & 4.637 & 4.833 & 5.011 & 5.04 & 5.011 \\
\hline & $(0.00)$ & $(0.00)$ & $(0.00)$ & $(0.00)$ & $(0.00)$ \\
\hline \multirow[t]{2}{*}{1978} & & 4.547 & 5.011 & 5.011 & 4.994 \\
\hline & & $(0.00)$ & $(0.00)$ & $(0.00)$ & $(0.00)$ \\
\hline \multirow[t]{2}{*}{1981} & & & 4.994 & 5.04 & 4.940 \\
\hline & & & $(0.00)$ & $(0.00)$ & $(0.00)$ \\
\hline \multirow[t]{2}{*}{1984} & & & & 4.708 & 4.297 \\
\hline & & & & $(0.00)$ & $(0.00)$ \\
\hline \multirow[t]{2}{*}{1987} & & & & & 2.939 \\
\hline & & & & & $(0.03)$ \\
\hline \multicolumn{6}{|c|}{ Panel (c): Price recovery } \\
\hline \multirow[t]{2}{*}{1975} & -4.672 & -5.04 & -5.04 & -5.04 & -5.04 \\
\hline & $(0.00)$ & $(0.00)$ & $(0.00)$ & $(0.00)$ & $(0.00)$ \\
\hline \multirow[t]{2}{*}{1978} & & -4.905 & -5.04 & -5.04 & -5.04 \\
\hline & & $(0.00)$ & $(0.00)$ & $(0.00)$ & $(0.00)$ \\
\hline \multirow[t]{2}{*}{1981} & & & -4.958 & -5.04 & -4.994 \\
\hline & & & $(0.00)$ & $(0.00)$ & $(0.00)$ \\
\hline \multirow[t]{2}{*}{1984} & & & & -4.940 & -4.904 \\
\hline & & & & $(0.00)$ & $(0.00)$ \\
\hline \multirow[t]{2}{*}{1987} & & & & & -3.689 \\
\hline & & & & & $(0.00)$ \\
\hline
\end{tabular}

$p$ value that the $z$ statistic is different from zero in parentheses.

the profitability margin, there will be a compression in profitability in later periods as increasing competition brings severe pressures to bear on the revenue streams of extant firms. The test results are shown in Table II. 
The test of a difference in the profitability change ratio between the years 1975 and 1978 is not significant. However, between 1978, when price competition entered the industry, and 1984 profitability has fallen significantly. In 1981 the institutional changes likely to take place were put in process. Incumbent firms may have exercised market power to gain an advantage in profits, as the increase in the ratio between 1981 and 1984 shows. However, when divestiture took place and key parts of the industry were deregulated in 1984, profits thereafter fell. The ratio drops further between 1984 and 1987, and between 1987 and 1990, with such drops being statistically significant.

\section{THE IMPACT OF PRODUCTIVITY}

Since a firm can face pressures to be cost efficient, or focus on generating revenues to earn greater profits, attaining productivity in operations is one of the key means of contributing to a firm's profitability. Reviewing Table II we see that the productivity ratio in the sample of firms increases consistently, from 1975 to 1978,1978 to 1981, 1981 to 1984,1984 to 1987 and 1987 to 1990. Details of the statistical tests undertaken are presented in panel (b) of Table II.

The increases in the ratio between each pair of years compared, 1975 to 1978 , 1978 to 1981,1981 to 1984,1984 to 1987 and 1987 to 1990 are statistically significant, and the fact that the productivity ratio has monotonically increased over the entire period 1973 to 1987 is also highlighted by a review of Table II across the diagonal. Increases in the ratio between the succeeding pairs of years are all positive and are statistically significant. That the most significant betterment in productivity takes place between 1981 and 1984, and the rises between 1984 and 1987 and 1987 and 1990 are also very high, is shown in Table I. Following divestiture the firms have had to find other sources of improved performance, given that our results reveal a significant decline in profitability between 1984 and 1990 . One key source has been significantly increased productivity. Our second expectation, that with increasing opening up of markets the productivity of telecommunications firms will increase, is also validated, and the evidence is consistent with that of other researchers.

\section{THE IMPACT ON PRICE RECOVERY}

Next, we have posited that the ability of a regulated firm to recover high prices for its products will decline as deregulation leads to the intensification of competition; and, we will expect such declines to continue if a deregulated environment becomes intrinsic in an industry. In Table I we have noted that the price recovery change sharply declines in every period from 1975 to 1990 . This suggests that competition from new entrants brings extremely strong pressures on the erstwhile monopoly telecommunication firms to reduce their prices. Statistical tests results on this ratio are given in panel (c) of Table II. From Table II we also note that the decrease 
in the price recovery ratio is monotonic throughout the period of our study. Each succeeding year ratio is very significantly less than that of the previous year, and a reading across the diagonal of the results indicates this to be the trend between all pairs of years. These results validate our expectations and our evidence is consistent not only with the assumptions of theory, but also with other extant studies.

\section{Summary and Future Directions}

Analyzing the impact changes such as market liberalization on various dimensions of firm performance is a major area for empirical researchers. We have carried out one such study in the context of the U.S. telecommunications industry. The results of our study help validate some assumptions as to how environmental changes such as market libcralization impact on firms. The implications of these assumptions have import for our understanding of firm-level change. While pressures on margins and prices are likely to develop, firms face greater incentives to adopt efficiency-oriented behavior, leading to increases in operating efficiencies. All these expectations hold up in our study of the U.S. telecommunications industry over a period of major strategic change between 1975 and 1990. From the warm sun of a regulated industry in 1975, in transition to a scenario in 1990 where cold showers of competitive pressures run, firms have significantly changed their behavior.

We demonstrate that while overall profitability margins may rise and then fall as a result of the macro-level market forces, separate micro-level components of firm performance that impact such profitability also change significantly. With increasing competition we expected the price recovery ability of firms to drop as more suppliers entered the markets of existing players, seeking customers. However, to counteract such trends firms increase their operational efficiencies through increasing productivity. As a result of such focusing and paying attention to operating efficiencies, firms are able to counteract and offset the drop in profits likely to be caused by a drop in the price recovery ratio.

Though our study is anchored in one industry, the implications are generalizable elsewhere. Even if overall performance, as measured by the profitability margin, stays the same or may not vary much, the underlying factors that influence it can change dramatically. We thus use our results to demonstrate some temporal patterns about the impact of changes such as market liberalization, though information on future years' performance of the firms concerned can add more meaning to the results. It is possible that over time pressures of competition may exacerbate, so as to have a $U$ or an inverted $U$-shaped impact on all dimensions of performance. We can use future years' time-series data then to evaluate whether the underlying patterns exhibited in the current study do remain stable over time, and draw general conclusions about the firm-level impact of market changes.

\section{References}

American Productivity Center (1981) Total Performance Measurement. Houston, TX. 
Bailey, E. E. (1986) 'Price and Productivity Change Following Seregulation: The U.S. Experience', Economic Journal, 96, 1-17.

Banker, R. D., Datar, S. M., and Kaplan R. S. (1989) 'Productivity Measurement and Management Accounting', Journal of Accounting, Auditing and Finance, Fall, 528-554.

Banker, R. D., Chang, Hsi-hui, and Majumdar, S. K. (1993) 'Analyzing the Underlying Dimensions of Firm Profitability', Managerial and Decision Economics, 14.1, 25-36.

Banker, R. D., Chang, Hsi-hui, and Majumdar, S. K. (1995) 'The Consequences of Evolving Competition on the Components of Firms' Profits: Recent Evidence from the U.S. Telecommunications Industry', Information Economics and Policy, 7.1, 37-56.

Bolter, W. G., McConnaughey, J. W., and Kelsey, F. J. (1990) Telecommunications Policy for the 1990 s and Beyond, M.E. Sharpe, Inc, Armonk, NY.

Cowling, K. and Waterson, M. (1976) 'Price-Cost Margins and Market Structure', Economica, 43, 267-274.

Crandall, R. W. (1991) 'Efficiency and Productivity', in B. G. Cole (ed.), After the Breakup: Assessing the New Post-AT\&T Divestiture Era, Columbia University Press, New York, NY.

Crew, M. A., Jones-Lee, M. W., and Rowley, C. K. (1971) 'X-Theory Versus Management Discretion Theory', Southern Economic Journal 38, October, 173-184.

Federal Communications Commission (Annual) Statistics of Communications Common Carriers, Washington, D.C.

Gaskins, D. (1971) 'Dynamic Limit Pricing: Optimal Pricing Under the Threat of Entry', Journal of Economic Theory, 3, 306-322.

Gill, G., McFarlan, W. and O'Neill, J. P. (1989) 'Bypass of Local Operating Telephone Companies: Opportunities and Policy Issues', in S. P. Bradley and J. A. Hausman (eds.), Future Competition in Telecommunications, Harvard Business School Press, Boston.

Huber, P. W. (1987) The Geodesic Network: 1987 Report on Competition in the Telephone Industry, U.S. Department of Justice, Antitrust Division, Washington, D.C.

Kahn, A. E. (1988) The Economics of Regulation: Principles and Institutions, The MIT Press, Cambridge, MA.

Kamien, M. and Schwartz, N. (1971) 'Limit Pricing and Uncertain Entry', Econometrica, 39, 441454.

Kendrick, J. W. (1986) Measuring Company Productivity: Handbook with Case Studies, Johns Hopkins University Press, Baltimore, MD.

Leibenstein, H. (1976) Beyond Economic Man, Harvard University Press, Cambridge, MA.

Majumdar, S. K. (1995) 'X-Efficiency in Emerging Competitive Markets: The Case of U.S. Telecommunications', Journal of Economic Behavior and Organization, 26(1), 129-144.

Meyer, J. R., Wilson, R. W., Baughcum, M. A., Burton, E., and Caouette, L. (1980) The Economics Competition in the Telecommunications Industry, Oelgeschlager, Gunn and Hain, Publishers, Inc, Cambridge, MA.

Mitchell, B. and Vogelsang, I. (1991) Telecommunications Pricing: Theory and Practice, Cambridge University Press, New York.

Perl, L. J. (1988) 'Economic Consequences of Competition in Telecommunications', Paper presented at the International Telecommunications Society Seventh Bi-Annual Conference, Cambridge, MA.

Rose, N. (1987) 'Labor Rent-Sharing and Regulation: Evidence from the Trucking Industry', Journal of Political Economcy, 95, 1146-1178.

Selten, R. (1986) 'Elementary Theory of Slack Ridden Competition', in J. E. Stiglitz and G. F. Mathewson (eds.), New Developments in the Analysis of Market Structure, The MIT Press, Cambridge, MA.

Shepherd, W. G. (1983) 'Concepts of Competition and Efficient Policy in the Telecommunications Sector', in E. M. Noam (ed.), Telecommunications Regulation: Today and Tomorrow, Harcourt, Brace and Jovanovich, Inc, New York.

Shepherd, W. G. (1986) 'On the Core Concepts of Industrial Economics', in H. W. de Jong and W. G. Shepherd (eds.), Mainstreams in Industrial Organization, Martinus Nijhoff Publishers, Dordrecht. 
Shepherd, W. G. (1990) The Economics of Industrial Organization, Prentice Hall, Inc. Third Edition, Englewood Cliffs, N.J.

Spence, A. M. (1977) 'Entry, Capacity, Investment and Oligopolistic Pricing', Bell Journal of Economics, 8, 534-544.

Spence, A. M. (1986) 'Cost Reduction, Competition and Industry Performance', in J. E. Stiglitz and G. F. Mathewson (eds.), New Developments in the Analysis of Market Structure, The MIT Press, Cambridge, MA.

Vietor, R. (1989) 'AT\&T and the Public Good: Regulation and Competition in Telecommunications. 1910-1987', in S. P. Bradley and J. A. Hausman (eds.), Future Competition in Telecommunications, Harvard Business School Press, Boston.

Wenders, J. T. (1989) 'Deregulating the Local Exchange', in J. H. Alleman and R. O. Emmerson (eds.), Perspectives on the Telephone Industry: The Challenge for the Future, Harper and Row, Publishers, New York.

Wilcoxon, F. (1945) 'Individual Comparisons by Ranking Methods', Biometrica, 1, 80-83. 